\title{
Aplicación de polígonos Thiessen para la definición y análisis de áreas de influencia del sistema de salud en ciudades costeras del estado de Quintana Roo
} Application of Thiessen polygons for the definition and analysis of areas of
influence of the health system in coastal cities of the state of Quintana Roo

\author{
Alicia Cuza-Sorolla* \\ María Luisa Hernández-Aguilar* \\ Miguel Ángel Barrera-Rojas*
}

Recibido: mayo 19 de 2020.

Aceptado: septiembre 22 de 2020.

\begin{abstract}
Resumen
Los Sistemas de Información Geográfica (SIG), hoy en día son herramientas aplicadas a investigaciones de diversa índole, tal es el caso de la Geografía de la Salud. En el presente trabajo se utilizan los polígonos Thiessen como herramienta de aproximación, para determinar las áreas de influencia de las unidades de salud en cuatro ciudades costeras del estado de Quintana Roo: Cancún, Playa del Carmen, Tulum y Chetumal. Este ejercicio se presenta desde el contexto de la pandemia generada por el virus SARS-CoV-2 (COVID-19), con la intención de determinar la capacidad instalada de las unidades médicas, una de las variables a medir son los hospitales ubicados en zonas urbanas en función de la densidad de población. Si bien, la densidad de población es una variable importante pretendimos también incluir la variable de marginación desde la perspectiva de una situación social de desventaja. Esta herramienta de aproximación, permitió realizar un análisis de la distribución de las unidades de salud para 2019. Entre los principales resultados, se advierte que la ciudad de Cancún cuenta con la mayor cantidad de unidades de salud en comparación con las otras ciudades objeto de estudio, pero también con mayores valores de densidad poblacional y con áreas de alto grado de marginación. En contraparte, Tulum es el caso con mayor desventaja al contar con sólo dos unidades de salud. Los resultados fueron reflejados en mapas y tablas para cada ciudad. Este artículo forma parte del proyecto en elaboración para la atención a la emergencia COVID-19 en Quintana Roo, de la Universidad de Quintana Roo.
\end{abstract}

Palabras claves: áreas de influencia, SIG, salud, marginación, COVID-19.

\begin{abstract}
Geographic Information Systems (GIS) today are tools applied to research of various kinds, such as the case of Health Geography. In this work, the Thiessen polygons are used as an approximation tool to determine the areas of influence of the health units in four coastal cities in the state of Quintana Roo: Cancún, Playa del Carmen, Tulum, and Chetumal. From the context of the pandemic generated by the SARS-CoV-2 virus (COVID-19), and to determine the installed capacity of medical units, one of the variables to be measured are hospitals located in urban areas by population density. Although population density is an important variable, we also wanted to include the marginalization variable from the perspective of a disadvantaged social situation. This approximation tool allowed an analysis of the distribution of health units for 2019. Among the main results, it is noted that the city of Cancun has the largest number of health units compared to the other cities under study, but also with higher values of population density and high marginalization values. In contrast, Tulum is the case with the greatest disadvantage since it only has two health units. The results were reflected in maps and tables for each city. This article is part of the project in preparation for the emergency care COVID-19 in Quintana Roo, of the University of Quintana Roo.
\end{abstract}

Keywords: Areas of influence, GIS, health, marginalization, COVID-19.

*Universidad de Quintana Roo, México. Correos electrónicos: alycuza@gmail.com, malu@uqroo.edu.mx, miguel.barrera@uqroo.edu.mx 


\section{Introducción}

Los Sistemas de Información Geográfica (SIG) hoy en día son herramientas aplicadas a investigaciones de diversa índole del campo de la Geografía y de otras disciplinas, por ejemplo, en cuestiones ambientales, fenómenos de carácter social y económico, arquitectura, servicios de salud, entre otros. Los SIG se han convertido en una herramienta esencial para el manejo y tratamiento de los datos geográficos de problemas prácticos, entre los que destaca la gestión de infraestructura física, la realización de grandes bases de datos catastrales, en la planificación urbana y ambiental, por citar algunos. Por consiguiente, este instrumento parte de la Geografía y se utiliza para el estudio de localizaciones, distribuciones, asociaciones, interacciones y evoluciones espaciales de las relaciones entre las sociedades y su entorno (Buzai y Baxendale, 2006; Aragón et al., 2018; Pizarro et al., 2003; Sánchez, 2017).

El software de SIG utiliza las llamadas de aproximación (proximity), mediante las cuales se pueden generar diferentes análisis, como el de áreas de influencia. La generación de área de influencia es una técnica que parte de la cartografía y el empleo de los SIG para ser aplicada al estudio de diferentes fenómenos sociales. De acuerdo con Buzai y Baxendale (2006), se centra en la distribución de puntos centrales y sus alcances espaciales. La localización de estos puntos, en el caso de las unidades de salud, es fundamental para entender su conexión con la demanda y cómo es el intercambio con la misma a través de la red de calles y vías de comunicación, ya que son los factores esenciales para analizar y comprobar el área de influencia para su alcance ideal. Considerando un comportamiento racional que lleva a la búsqueda del menor esfuerzo, las necesidades serán satisfechas en el centro de servicios más cercano minimizando así el desplazamiento.

En el presente trabajo se aplican técnicas de SIG, específicamente, la herramienta de polígonos Thiessen, en el contexto de la pandemia generada por el virus SARS-CoV-2 (COVID-19), con el objetivo de determinar la capacidad instalada de las unidades médicas, sobreponiendo variables de densidad de población y marginación, en cuatro ciudades costeras del estado de Quintana Roo, México. Este análisis permite establecer relaciones matemáticas entre elementos generando zonas de influencia con unas premisas matemáticas específicas. En este caso, una de las variables a medir son los hospitales ubicados en zonas urbanas por densidad población. Si bien, la densidad de población es una variable importante, también se incluye la variable de marginación desde la perspectiva de una situación social de desventaja para el acceso a servicios de salud.

Este artículo forma parte de un proyecto para la atención a la emergencia COVID-19 en Quintana Roo, México, el cual está en fase de desarrollo por académicos de la Universidad de Quintana Roo, entre los que se encuentran especialistas de la salud, quienes señalan que, a fin de dar respuesta a una pandemia, no sólo el uso de las tecnologías para la salud es crucial para la prevención, el diagnóstico, el tratamiento y la rehabilitación de 
pacientes, sino que es necesario desarrollar investigación multidisciplinaria que permita analizar el contexto de la pandemia y la contingencia que se ha generado.

En ese sentido, los especialistas del área médica señalan que es menester abordar la cobertura de salud pública; por ello, este documento resultará indispensable, desde la Geografía de la Salud, para los responsables de la salud pública en aras de asegurar el acceso oportuno a las unidades de salud por parte de la población que pudieses demandar estos servicios.

El objetivo general del artículo es determinar las áreas de influencia a efectos de conocer la capacidad instalada de las unidades médicas en el contexto de la pandemia SARSCov-2 (COVID-19) en ciudades costeras del estado de Quintana Roo, México. Para ello, se analiza la localización y la distribución de las unidades médicas de las zonas urbanas, objeto de estudio, teniendo en cuenta la densidad de población, pues permite conocer la demanda hacia esos servicios; es decir, la cantidad de población a la que corresponde la atención médica de una instalación, así como el grado de marginación urbana desde la perspectiva de una situación social como desventaja para el acceso a servicios de salud.

Se parte de la hipótesis de que las unidades de salud se encuentran distribuidas inequitativamente. Existen unidades del sector privado donde la población está más marginada y no tiene acceso, por lo cual tienen que trasladarse a unidades públicas, recargando los servicios de atención en el contexto de la pandemia.

Si bien se muestra la técnica y el procedimiento empleados para la confección de las áreas de influencia y el análisis posterior, lo ideal hubiese sido mostrar datos más actualizados, pero, por la situación actual, el censo poblacional del Instituto Nacional de Estadística y Geografía (INEGI) 2020, se vio interrumpido. Bajo estas condiciones, fue inminente trabajar con datos de años anteriores, particularmente la división por Área Geoestadística Básica (AGEB) 2010 del INEGI, así como con datos del grado de marginación urbana 2010, proporcionados por el Consejo Nacional de Población (CONAPO). La información disponible de años más actuales se encuentra a escala de municipio. Uno de los principales aportes del presente trabajo es el análisis más detallado a nivel de AGEB para las ciudades objeto de estudio.

\section{Aspectos conceptuales}

El análisis de las áreas de influencia para cada unidad de salud por cada ciudad tomada como objeto de estudio parte de la base de los datos de densidad poblacional y del grado de marginación urbana; variables que permiten entender el contexto de las ciudades estudiadas y la dimensión del problema que en este periodo se ha desatado. Todo este análisis comienza con la teoría de la Geografía de la Salud, pues es una de las líneas temáticas que tiene cabida en la situación actual. 


\section{Geografía de la Salud}

En la actualidad, un tema de mayor receptividad en el tratamiento cuantitativo de datos espaciales mediante los SIG es el análisis espacial de la salud. Como menciona Buzai (2016), este enfoque permite desarrollar metodologías para el estudio de las distribuciones y asociaciones espaciales entre enfermedades y condiciones sociales, así como de las distribuciones de los centros de atención y el potencial de la demanda.

Para Ramírez (2017), el empleo de los SIG en el campo de la Geografía de la Salud se enfoca al análisis de un evento o de situaciones de salud en un área geográfica y una población específica; analiza distribución de enfermedades, patrones o diferencias de la situación de salud de distintos niveles de agregación, identificación de grupos de alto riesgo, vigilancia y monitoreo en salud pública, entre otros. Además -comenta-, este vínculo da soporte a las decisiones en el planteamiento de los servicios de salud; es decir, hace aportes al proceso de toma de decisiones dentro de un territorio sobre los servicios de salud.

Según Howe (1986), la Geografía de la Salud se vincula en cuatro dimensiones: biología humana, ambiente, forma de vida y sistema de asistencia médica; este último aborda la dimensión espacial del sistema de atención al estudiar la relación entre los centros de atención y la población de demanda. A esta línea temática corresponden los análisis de las áreas de influencia a través de los polígonos Thiessen.

\section{Marginación}

El concepto de marginación se puede situar a partir de los textos de Durkheim; en específico, El suicidio (Durkheim, 1982), en donde se plantea la idea de que la segregación y la exclusión, entre otros factores, que algunos individuos viven, constituyen un cúmulo de hechos sociales o conciencia colectiva que explican el suicidio. Este fenómeno de nula integración, segregación o de expulsión hacia los márgenes de la sociedad (Cuthill, 2019; Castro, 2018) comenzó a poner en tela de juicio si el concepto de pobreza era suficiente para explicar a los sectores más desfavorecidos y vulnerables de la sociedad.

Sin embargo, de acuerdo con Elias y Scotson (2015), el margen de la sociedad es un imaginario de sumo volátil, pues no necesariamente los pobres son los únicos excluidos o en el margen de la sociedad. De igual modo, los trabajos de Reid (2017), Herrero (2018), Castro (2018), Cuthill (2019) y Debnath (2020) señalan que en los estratos más pobres también hay diferencias entre los márgenes sociales; por ejemplo, el grado de marginación entre pobres urbanos y pobres rurales es distinto; lo mismo sucede si en la ecuación se incluye a los indígenas, a los sin hogar, a mujeres indígenas o a migrantes legales e ilegales. De ahí la importancia de abordar conceptualmente a la marginación en este documento.

Es trascendental retomar el sentir de Quijano (1972), quien plantea que la marginación se manifiesta desde cinco características: 
1) La ocupación de los marginados. "Los roles ocupacionales que son marginados de las relaciones hegemónicas de producción son los artesanales, los de la pequeña producción de servicios y el pequeño comercio" (Quijano, 1972: 91); es decir, se puede ser establemente ocupado en términos laborales y ser marginado al mismo tiempo.

2) El mercado de las ocupaciones marginadas. Quijano (1972: 92) señala que la ocupación laboral de la población en situación de marginación se ubica "en las ramas de actividad no definitivamente industrializadas o tecnificadas, como las de la construcción, las actividades de servicio no-productivo y manual".

3) Movilidad ocupacional marginal. Quijano (1972: 93) deja ver la idea de que la población marginada en el algún punto podría desarrollar actividades de "pequeña burguesía marginal", sin embargo, sólo las podrá desempeñar de forma temporal, ya que "las actividades de la pequeña burguesía marginal suponen la posesión de los recursos necesarios, sea para la artesanía, la pequeña producción de servicios o el pequeño comercio. Y eso, dada la inestabilidad y pequeñez de los ingresos de los asalariados marginales, constituye una forma de barrera importante para esas formas de actividad".

4) El ingreso marginal. Es bajo y precario sin importar si se manifiesta en forma de salario marginal, de empleo, lucro marginal o de autoempleo.

5) Consumo marginal. Quijano (1972) advierte que el nivel de consumo de la población marginal habrá de ser abordado con cautela, pues, debido a sus ingresos precarios, la única forma de acceder a canastas de bienes y servicios intermedias y superiores es a través de asistencialismo, el cual no necesariamente se refleja en forma de recursos monetarios, sino de infraestructura deficiente y programas que buscan soluciones mediáticas y de corto plazo (Loktieva, 2016; Nieto, Nicasio, Martín \& García, 2017; Reid, 2017).

En el caso específico de México, el gobierno federal ha puesto especial cuidado en medir de diferente manera la pobreza y la marginación; mientras que la primera se asocia a condiciones de vida y bienestar económico (CONAPO, 2010), la segunda ha sufrido leves modificaciones con el paso del tiempo; sin embargo, en todas sus concepciones hace referencia a segregación.

Para el diseño operacional del índice de marginación de 2000, la marginación fue definida como "un fenómeno multidimensional y estructural originado, en última instancia, por el modelo de producción económica expresado en la desigual distribución del progreso, en la estructura productiva y en la exclusión de diversos grupos sociales, tanto del proceso como de los beneficios del desarrollo" (CONAPO, 2000: 11). Según el (CONAPO, 2013: 11), esta marginación "se asocia a la carencia de oportunidades sociales y la ausencia de capacidades para adquirirlas o generarlas, pero también a privaciones e inaccesibilidad a bienes y servicios fundamentales para el bienestar". Por su parte, para el diseño del índice de marginación del 2010 la definción operacionalizada dicta lo siguiente: 
Fenómeno estructural [que] expresa la dificultad para propagar el progreso en el conjunto de la estructura productiva, pues excluye a ciertos grupos sociales del goce de beneficios que otorga el proceso de desarrollo. La precaria estructura de oportunidades sociales para los ciudadanos, sus familias y comunidades los expone a privaciones, riesgos y vulnerabilidades sociales que, a menudo, escapan al control personal, familiar y comunitario (CONAPO, 2010: 11).

\section{Densidad de población}

En la actualidad, el desarrollo de las tecnologías y el aumento del uso de los SIG ha facilitado y promovido la incorporación de la dimensión espacial en el análisis de fenómenos y procesos sociales, entre ellos demográficos (Reyna, 2006), a tráves de escalas geográficas. Entre sus aplicaciones vinculadas a estas temáticas se encuentran la conformación de inventarios de información exhaustiva de unidades territoriales y la formulación de modelos estadísticos que muestren la espacialidad e interacción de fenómenos con las dimensiones territorial y ambiental.

La densidad de población es una variable que forma parte de los estudios demográficos, los cuales han mantenido la dimensión espacial junto con temas de migración, distribución de población, procesos de urbanización y proyecciones demográficas. Reyna (2006) menciona algunos procedimientos de análisis espacial vinculados a cuestiones demográficas; entre ellos destacan los análisis de proximidad, pues permiten identificar áreas cuyas características de análisis tienen el mismo valor o categoría y mantienen continuidad.

Según INEGI (2015), en México, la distribución de población es desigual; en algunas regiones se concentra mucha más cantidad de población, mientras que en otras es escasa. Esta institución define a la densidad de población como la relación entre un espacio determinado y el número de personas que lo habitan. Según la encuesta intercensal del INEGI (2015), para ese año la densidad poblacional del estado de Quintana Roo era de 34 $\mathrm{hab} / \mathrm{km} 2$.

\section{Polígonos Thiessen}

Por otra parte, la metodología seleccionada para desarrollar en el presente trabajo es la propuesta por Buzai (2016), donde utiliza la herramienta de los polígonos Thiessen para la generación de áreas de influencia de los centros de atención primaria de salud en la ciudad de Luján, Argentina.

La herramienta Thiessen distribuye proporcionalmente una cobertura de puntos para generar polígonos de áreas de influencia definidas a partir de cada punto. Cualquier ubicación dentro de un polígono de Thiessen está más cerca de su punto asociado que de cualquier otra entidad de entrada de puntos. En este sentido, si esos puntos son centros de salud, su poder de atracción podría ser medido a partir de su capacidad de servicio, por lo cual la influencia de cada centro será mayor cuanto más población atienda. 
Esta metodología, se utiliza para el estudio de la distribución espacial y temporal de variables hidrológicas (temperatura, precipitación, infiltración) y en aplicaciones ingenieriles. Autores como Aragón et al. (2018); Pizarro, Ramírez y Flores (2003); y Sánchez (2017) dan una muestra de ello. De la misma manera, se han empleado en la delimitación del área de influencia del aeropuerto internacional de Querétaro, México, por el Instituto Mexicano del Transporte (2010). Este método nos permitió identificar las áreas de influencia (polígonos Thiessen) de las unidades de salud en las principales ciudades costeras del estado de Quintana Roo (ver figura 1) y relacionarlas con datos de densidad poblacional y grado de marginación por área geoestadística básica (AGEB), identificando las zonas más vulnerables por carencias económicas y de acceso a servicios de salud, transcendentales para el monitoreo de la pandemia por el CoVID-19.

\section{Metodología}

El presente estudio está enfocado en cuatro ciudades costeras del estado de Quintana Roo (ver figura 1) localizadas al sureste de México, Cancún (municipio Benito Juárez), Playa del Carmen (municipio Solidaridad), Ciudad de Tulum (municipio Tulum) y Chetumal (municipio Othón P. Blanco); actualmente, en las dos primeras se concentra la mayor cantidad de casos del nuevo SARS-CoV-2.

Figura 1. Mapa de ubicación de las ciudades objeto de estudio

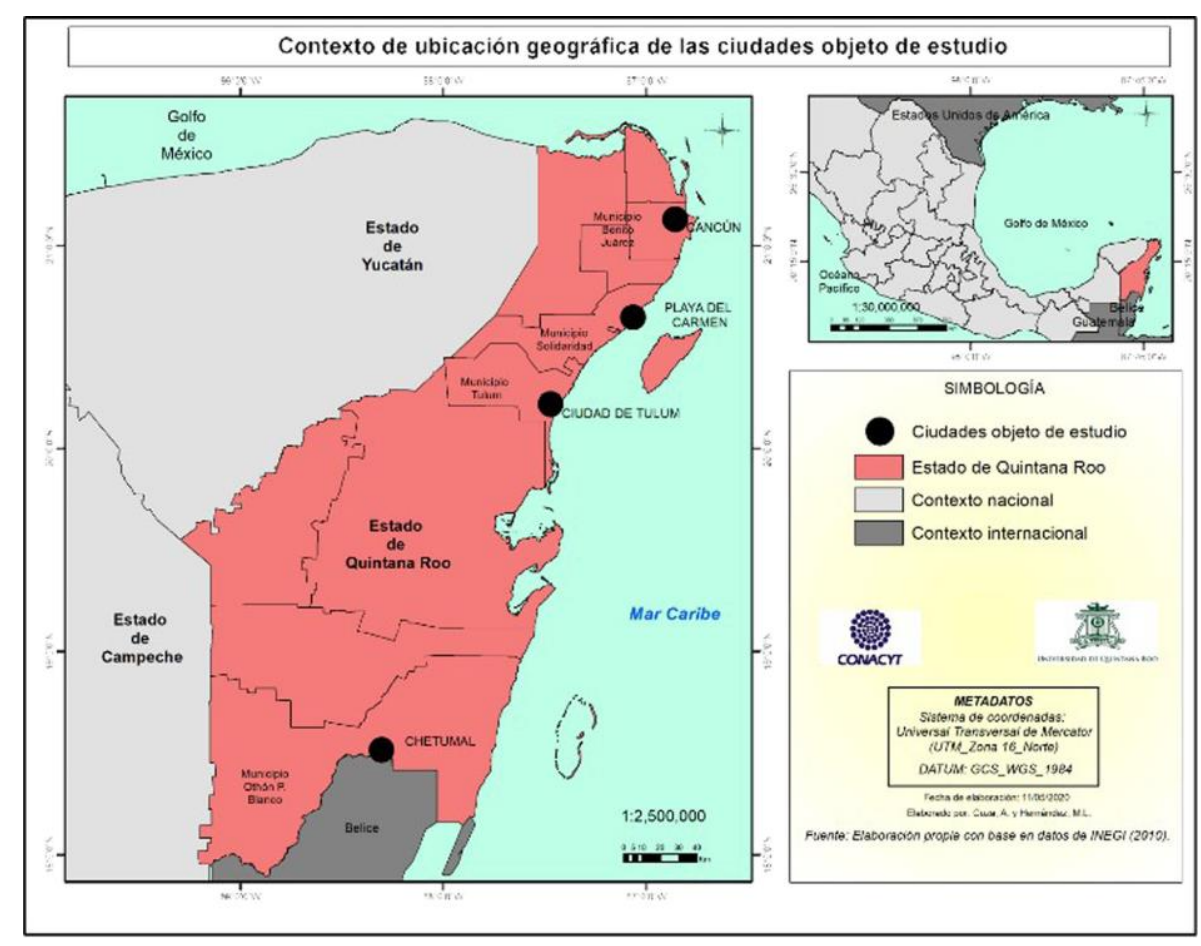

Fuente: elaboración propia con base en datos de INEGI (2010). 
La metodología empleada en el presente trabajo es una adaptación de los resultados de Buzai (2016), quien señala:

\footnotetext{
a medida que se hacen mayores y se superponen los polígonos, sus límites se ubican en la distancia media que existe entre cada par de puntos, y de esta manera, se genera un mosaico en el cual cada punto pasa a ser el centro de un determinado polígono y cada localización interior de un polígono se encuentra más cercano a su correspondiente centro que a cualquier otro.
}

Es decir, cada polígono individual se convierte en un área de influencia específica haciendo que el área de estudio se descomponga en un mosaico de diferentes áreas (ver figuras 2, 3, 4 y 5). Los pasos para llevar a cabo el procedimiento fueron:

- Contar con la información temática de distribución espacial de los puntos de oferta del servicio. En este caso, la distribución georreferenciada de las unidades de salud para las cuatro ciudades costeras se obtuvieron del Directorio Estadístico Nacional de Unidades Económicas (DENUE) del Instituto Nacional de Estadística y Geografía (INEGI, 2019).

- Utilizar la herramienta de los polígonos Thiessen y con esta base generar una nueva capa de información temática.

- Disponer de la capa de información temática de distribución espacial de la población de demanda potencial. En el caso del presente estudio, se trabajaron las variables densidad de población y grado de marginación urbana; ambas obtenidas de INEGI (2010) y del Consejo Nacional de Población (CONAPO, 2010), respectivamente.

- Determinar la pertenencia de cada radio censal a un polígono mediante superposición cartográfica. En este trabajo, la superposición cartográfica de los polígonos Thiessen se llevó a cabo sobre capas temáticas de las variables mencionadas: densidad de población y grado de marginación urbana, las cuales se cartografiaron previamente para las cuatro ciudades de estudio con el software ArcMap 10.3. La confección de los mapas de Grado de Marginación Urbana se realizó con base en los datos del Índice de Marginación Urbana de CONAPO (2010).

Las siguientes figuras muestran la aplicación de la metodología por cada ciudad en cuestión. Se presenta una figura para cada ciudad donde fue aplicada la metodología, con los nombres de cada una de las unidades de salud en su ubicación y el sector al que pertenecen, público o privado, los cuales se muestran en azul y rosado. El mosaico de líneas negras representa los polígonos Thiessen que se arrojaron como resultado. 
Figura 2. Polígonos Thiessen correspondientes a las unidades de salud de la ciudad de Cancún

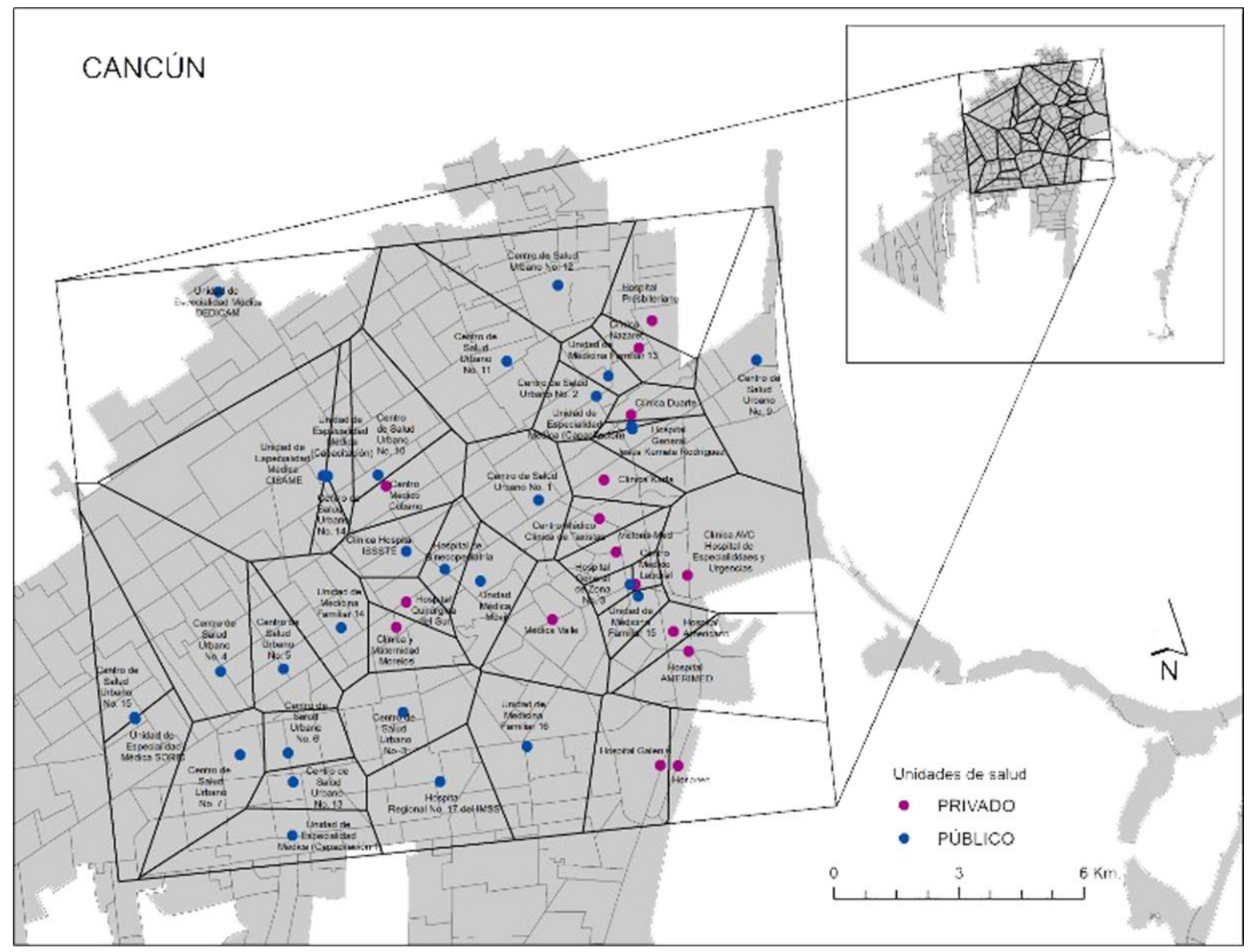

Fuente: elaboración propia con base en datos de INEGI (2010 y 2019).

Como se observa en la figura 2, en la zona centro de la ciudad de Cancún es donde las unidades de salud están más concentradas; se encuentran cercanas unas de otras y abarcan áreas de menor tamaño, mientras que hacia la periferia están más dispersas abarcando áreas mayores y dejando algunas zonas sin presencia de unidades de salud, lo cual implica que la población residente de estos lugares se tenga que trasladar hacia otros puntos de la ciudad para recibir atención médica, exponiéndose a mayor riesgo ante la situación actual de emergencia sanitaria.

Para el año 2010, Cancún contaba con un total de población de 628,306 habitantes (INEGI, 2010). Las estimaciones y proyecciones de la población por sexo y edad para localidades seleccionadas de Quintana Roo, 2010-2030, de CONAPO (2019), señalan que para la ciudad de Cancún la población total sería de 827,519 habitantes en 2019; por lo tanto, la demanda de servicios médicos en la ciudad aumentaría en gran medida. 
Figura 3. Polígonos Thiessen correspondientes a las unidades de salud de la ciudad de Playa del Carmen

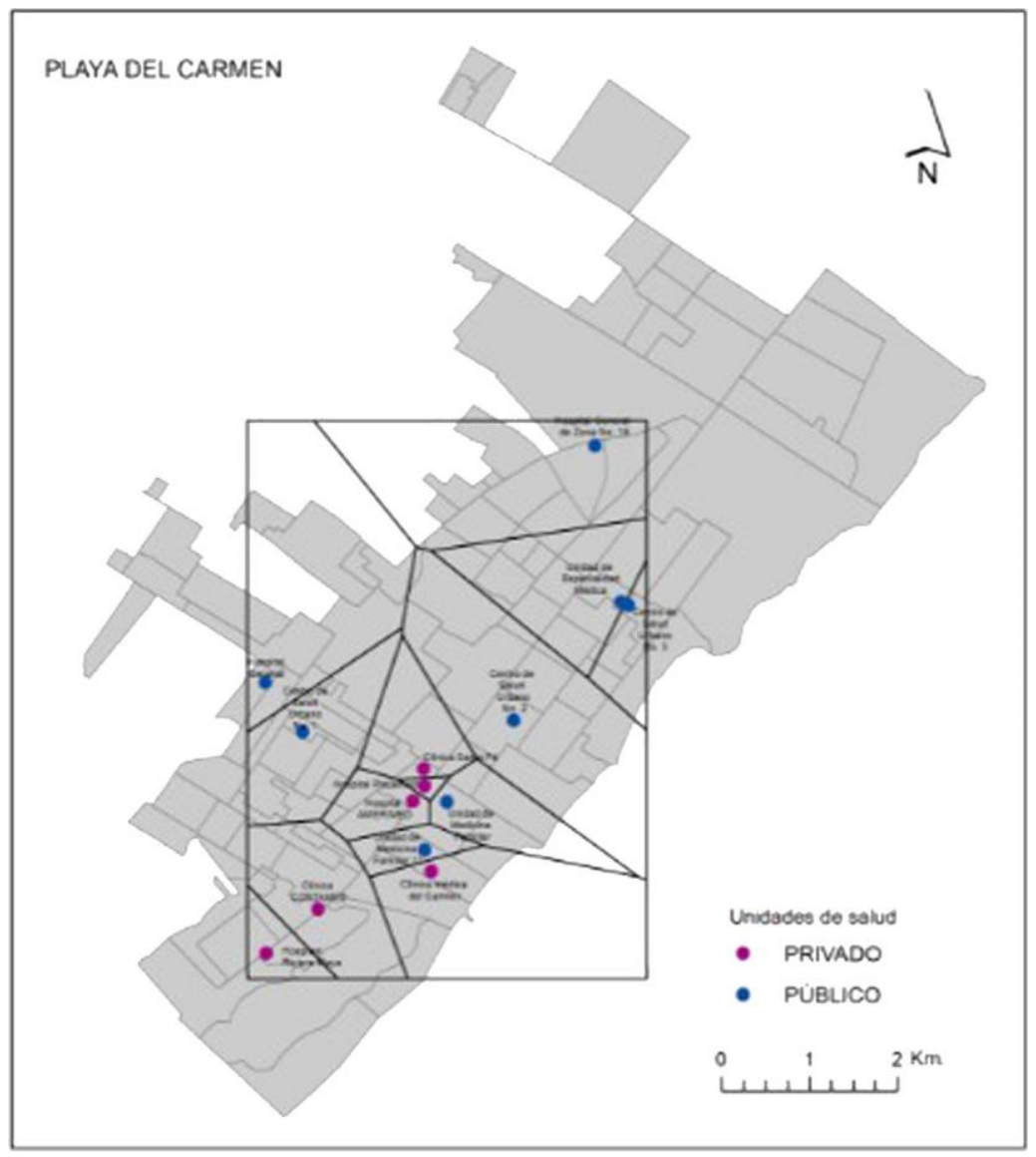

Fuente: elaboración propia con base en datos de INEGI (2010 y 2019).

De acuerdo con la figura 3, en la ciudad de Playa del Carmen la población total para ese año era de 149,923 habitantes (INEGI, 2010); la situación es similar a la observada en la ciudad de Cancún (ver figura 2), aunque la cantidad de unidades de salud tanto públicas como privadas disminuye como se puede observar en el cuadro 2, el cual se presenta más adelante. La mayor concentración de unidades de salud está hacia el sureste de la ciudad, y la mayoría de centros de salud son privados. Hacia la periferia de la ciudad, las unidades del sector público se encuentran mucho más dispersas abarcando áreas de mayor extensión.

La combinación de este resultado con la densidad de población se puede observar en la figura 7, donde se encuentran representadas las unidades de salud tanto privadas como públicas en conjunto con las variables de densidad de población y marginación para la ciudad de Playa del Carmen. Según CONAPO (2019), de acuerdo con sus proyecciones 2010-2030, la población total de la ciudad de Playa del Carmen en 2019 era de 221,166 habitantes, sin embargo, esa cifra puede estar rebasada en estos momentos. Lo anterior demanda un aumento en la atención médica y, por ende, mayor cantidad de instalación de centros de salud. 
Figura 4. Polígonos Thiessen correspondientes a las unidades de salud de la ciudad de Tulum

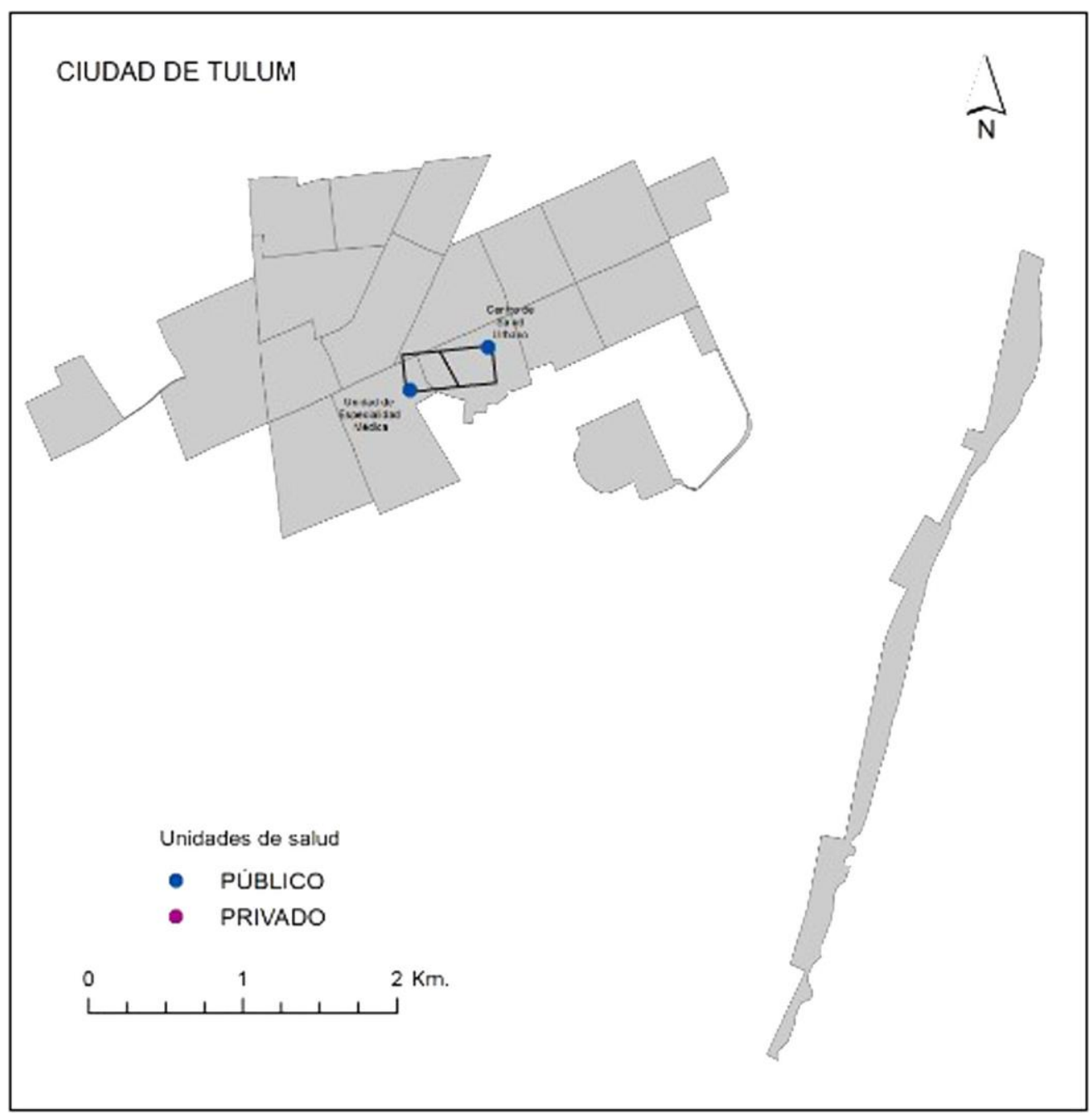

Fuente: elaboración propia con base en datos de INEGI (2010 y 2019).

El mosaico de polígonos Thiessen para la ciudad de Tulum abarca un área de muy poca extensión territorial. A simple vista se observa la carencia de unidades de salud en esta ciudad. La metodología empleada no puede mostrar las áreas de influencia ideales, ya que, por un lado, el dato de unidades de salud es mínimo y, por otro, existe una carencia de servicios de salud en esta ciudad costera, pues la mayoría de su población acude a las ciudades cercanas de Playa del Carmen o Cancún en busca del servicio.

Ante esta situación, se debe tener en cuenta que, según INEGI (2015), Tulum cuenta con una tasa de crecimiento demográfico del $12.5 \%$, en promedio, la cual está muy por encima de la media nacional: 1.4\% (CONAPO, 2019). De acuerdo con este crecimiento, la ciudad de Tulum en pocos años albergará una mayor cantidad de población de la que tiene actualmente, lo cual propiciará diversos problemas, entre ellos los de servicios de salud. 
Ahora bien, para la ciudad de Chetumal, la situación parece ser diferente a la analizada en las ciudades costeras anteriores. Como se observa en la figura 5, los polígonos generados abarcan gran parte de la ciudad, ya que las unidades de salud están mayormente distribuidas por toda su superficie urbana. Al noroeste de la ciudad, se identifica el Centro de Salud Urbano No. 1, el cual debe de brindar atención a un área de mayor extensión y por lo mismo a mayor población. La mayoría de los centros de salud en la ciudad son del sector público, con algunos privados, de acuerdo con el tamaño de población en esta ciudad, el acceso a los servicios de salud son de mayor facilidad por parte de la población.

La relación entre el área de influencia de cada unidad de salud y las variables estudiadas para esta ciudad puede observarse en la figura 9. En 2010, Chetumal contaba con un total de 151,243 habitantes, según INEGI (2010); de acuerdo con las proyecciones realizadas por CONAPO (2019), para el periodo 2010-2030, la población total de Chetumal aumentó a 190,791 habitantes y con ello se incrementará la demanda de atención médica y la cantidad de instalaciones para atención a la salud.

Figura 5. Polígonos Thiessen correspondientes a las unidades de salud de la ciudad de Chetumal

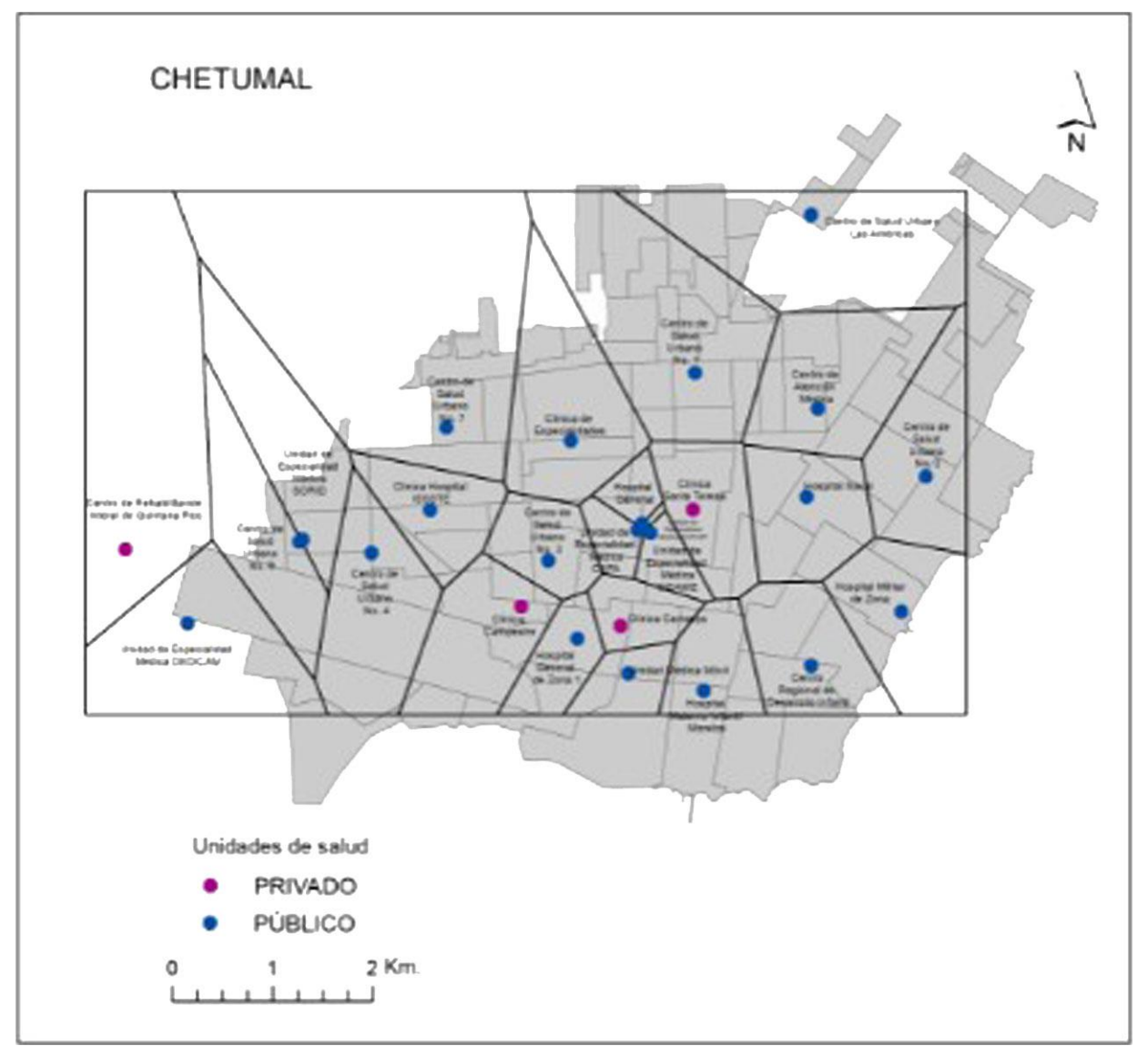

Fuente: elaboración propia con base en datos de INEGI (2010 y 2019). 


\section{Resultados}

Como parte de los resultados principales del trabajo, se obtuvieron los siguientes mapas a nivel de AGEB (2010) de cada ciudad con sus respectivas tablas explicativas, en donde se puede encontrar la información de cada unidad de salud de cada polígono Thiessen y su área de influencia en kilómetros cuadrados ( $\mathrm{km} 2)$; además, se observa la correspondencia de cada polígono y unidad de salud a un rango de valores cualitativos y cuantitativos de marginación y densidad poblacional, respectivamente.

Figura 6. Mapa del área de influencia de las unidades de salud, GMU (2010) y densidad de población para la ciudad de Cancún

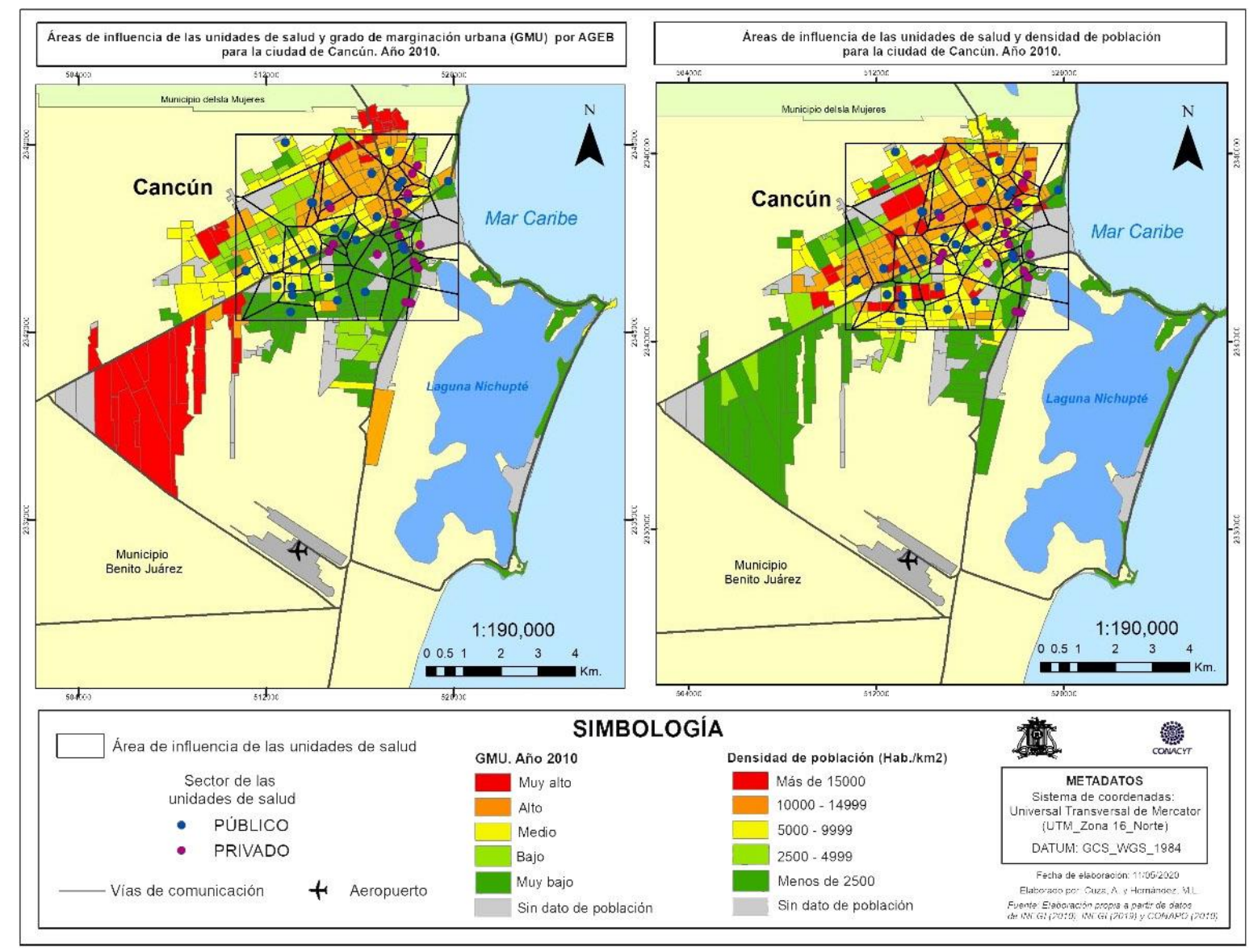

Fuente: elaboración propia con base en datos de INEGI (2010 y 2019) y CONAPO (2010). 
Cuadro 1. Densidad y grado de marginación urbana por unidades de salud y su área de influencia para la ciudad de Cancún

\begin{tabular}{|c|c|c|c|c|}
\hline POLÍGONOS & SECTOR & $\begin{array}{c}\text { ÁREA DE } \\
\text { INFLUENCIA } \\
\left(\mathbf{k m}^{2}\right)\end{array}$ & $\begin{array}{c}\text { DENSIDAD } \\
\left(\mathbf{h a b} / \mathbf{k m}^{2}\right)\end{array}$ & GMU \\
\hline Centro de salud urbano No. 7 & Público & 1.82 & 5,000 -más de 15,000 & Muy bajo-Medio \\
\hline Centro de salud urbano No. 3 & Público & 1.79 & 2,500-más de 15,000 & Muy bajo-Medio \\
\hline Clínica Hospital ISSSTE & Público & 0.89 & $5,000-14,999$ & Bajo-Medio \\
\hline Unidad de especialidad médica DEDICAM & Público & 7.83 & 2,500-más de 15,000 & Bajo-Alto \\
\hline Centro de salud urbano No. 12 & Público & 2.45 & 5,000- más de 15,000 & Medio-Muy alto \\
\hline Centro de salud urbano No. 9 & Público & 3.25 & Menos de 2,500-14,999 & Muy bajo-Alto \\
\hline Unidad de especialidad médica (Capacitación 1) & Público & 1.73 & $5,000-9,999$ & Muy bajo \\
\hline Unidad de especialidad médica SORID & Público & 1.65 & $5,000-9,999$ & Muy bajo-Muy alto \\
\hline Centro de salud urbano No. 15 & Público & 1.52 & $2,500-14,999$ & Muy bajo-Alto \\
\hline Centro de salud urbano No. 13 & Público & 0.84 & $5,000-9,999$ & Muy bajo-Medio \\
\hline Centro de salud urbano No. 6 & Público & 0.79 & 5,000-más de 15,000 & Bajo-Medio \\
\hline Centro de salud urbano No. 5 & Público & 1.33 & 2,500-más de 15,000 & Muy bajo-Medio \\
\hline Centro de salud urbano No. 4 & Público & 3.9 & $2,500-15,000$ & Bajo-Alto \\
\hline Hospital Regional No. 17 del IMSS & Público & 2.18 & $5,000-9,999$ & Alto-Muy bajo \\
\hline Unidad de medicina familiar No. 16 & Público & 2.85 & 2,500-más de 15,000 & Muy bajo \\
\hline Hospital general de la zona No. 3 & Público & 0.24 & Menos de $2,500-5,000$ & Muy bajo \\
\hline Hospital General Jesús Kumate Rodríguez & Público & 1.1 & $5,000-14,999$ & Medio-Alto \\
\hline Unidad de especialidad médica (Capacitación) & Público & 0.08 & $10,000-14,999$ & Alto \\
\hline Centro de salud urbano No. 1 & Público & 1.79 & 5,000-más de 15,000 & Medio-Alto \\
\hline Unidad de medicina familiar 15 & Público & 0.44 & Menos de 2,500-9,999 & Muy bajo \\
\hline Hospital de Ginecopediatría & Público & 0.63 & $5,000-9,999$ & Muy bajo-Bajo \\
\hline Unidad de especialidad médica (Capacitación) & Público & 0.55 & 5,000-más de 15,000 & Alto \\
\hline Unidad de especialidad médica CISAME & Público & 4.64 & Más de 15,000 & Alto \\
\hline Unidad médica móvil & Público & 1.17 & $2,500-9,999$ & Muy bajo-Medio \\
\hline Centro de salud urbano No. 10 & Público & 1.61 & $5,000-14,999$ & Medio-Alto \\
\hline Centro de salud urbano No. 14 & Público & 0.3 & Más de 15,000 & Alto \\
\hline Unidad de medicina familiar 14 & Público & 1.58 & 10,000-más de 15,000 & Medio-Alto \\
\hline Centro de salud urbano No. 2 & Público & 0.74 & 10,000 -más de 15,000 & Alto \\
\hline Centro de salud urbano No. 11 & Público & 4.08 & $5,000-14,999$ & Alto-Muy alto \\
\hline Unidad de medicina familiar 13 & Público & 0.49 & $10,000-14,999$ & Alto \\
\hline Hospital Americano & Privado & 0.66 & $2,500-9,999$ & Muy bajo \\
\hline Médica Valle & Privado & 1.91 & Menos de 2,500-9,999 & Muy bajo \\
\hline Hospital Amerimed & Privado & 2.8 & Menos de 2,500-4,999 & Muy bajo \\
\hline Hospiten & Privado & 2.82 & Menos de 2,500 & Muy bajo \\
\hline Hospital Galenia & Privado & 1.71 & Menos de 2,500 & Muy bajo \\
\hline Centro Médico Clínica de Taxistas & Privado & 0.55 & $5,000-14,999$ & Muy bajo \\
\hline Hospital Presbiteriano & Privado & 2.4 & $5,000-14,999$ & Bajo-Alto \\
\hline Clínica Nazaret & Privado & 0.66 & 5,000-más de 15,000 & Medio-Alto \\
\hline Clínica Duarte & Privado & 0.47 & $10,000-14,999$ & Medio-Alto \\
\hline Clínica y Maternidad Morelos & Privado & 0.78 & $5,000-9,999$ & Muy bajo \\
\hline Centro Médico Cubano & Privado & 1.03 & $10,000-14,999$ & Medio-Alto \\
\hline Hospital Quirúrgica del Sur & Privado & 0.51 & $5,000-9,999$ & Muy bajo \\
\hline Victoria Med & Privado & 0.64 & $2,500-9,999$ & Muy bajo-Bajo \\
\hline Clínica Hospital AVC & Privado & 3.15 & Menos de 2,500-4,999 & Muy bajo-Bajo \\
\hline Clínica Karla & Privado & 0.85 & $10,000-14,999$ & Alto \\
\hline Centro médico laboral & Privado & 0.15 & Menos de 2,500-5,000 & Muy bajo-Bajo \\
\hline
\end{tabular}

Fuente: elaboración propia.

En la ciudad de Cancún, como se observa en la figura 6, todas las unidades de salud tanto públicas como privadas se encuentran ubicadas hacia el centro de la ciudad, en áreas que cuentan con grado de marginación entre las clases de Muy bajo y Alto, donde reside población con valores de densidad entre 5,000 y 15,000 hab/km2 de acuerdo con las categorías obtenidas en la figura 6. 
Sin embargo, los AGEB ubicados hacia el suroeste de la ciudad, con grado de marginación Muy alto y con valores de densidad poblacional de menos de 2,500 hab/km2, no cuentan con la presencia de centros para la atención a la salud; por lo tanto, se puede deducir que quienes viven en estas áreas deben trasladarse hacia el centro de la ciudad para recibir atención médica.

Dos casos a destacar son la Unidad de Especialidad Médica DEDICAM y la Unidad de Especialidad Médica CISAME, ambas del sector público, ubicadas hacia la parte noroeste de la ciudad, con las áreas de influencia de mayor extensión dentro de la ciudad $(7.83 \mathrm{~km} 2$ y $4.64 \mathrm{~km} 2$, respectivamente) abarcando AGEB con valores de densidad poblacional de hasta 15,000 hab/km2 y grado de marginación de Bajo a Alto (ver cuadro 1).

Figura 7. Mapa del área de influencia de las unidades de salud, GMU (2010) y densidad de población para la ciudad de Playa del Carmen

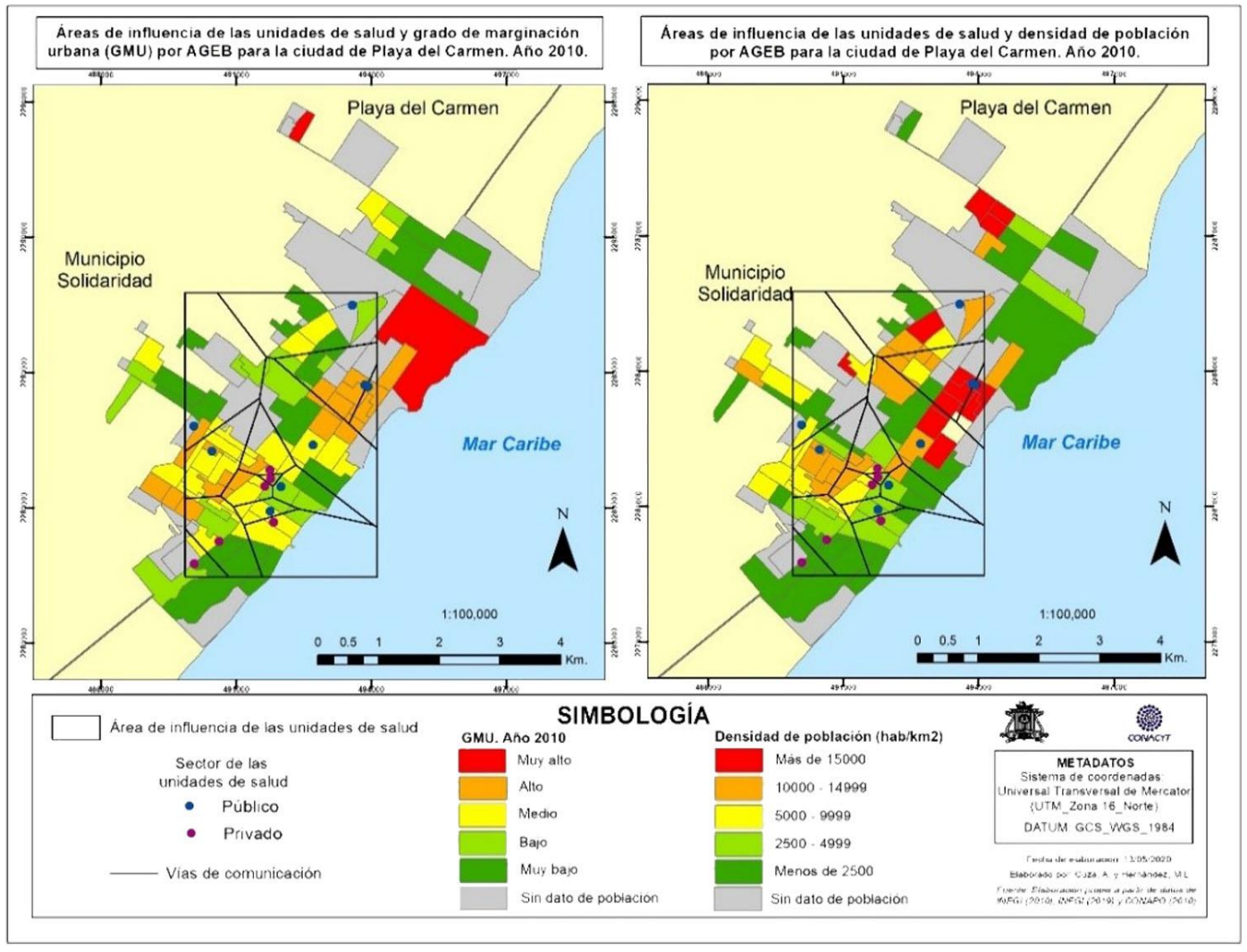

Fuente: elaboración propia con base en datos de INEGI (2010 y 2019) y CONAPO (2010). 
Cuadro 2. Densidad y grado de marginación urbana por unidades de salud y su área de influencia para la ciudad de Playa del Carmen

\begin{tabular}{|c|c|c|c|c|}
\hline POLÍGONOS & SECTOR & $\begin{array}{c}\text { ÁREA DE } \\
\text { INFLUENCIA } \\
\left(\mathrm{km}^{2}\right)\end{array}$ & $\begin{array}{c}\text { DENSIDAD } \\
\left(\mathrm{hab} / \mathrm{km}^{2}\right)\end{array}$ & GMU \\
\hline Hospiten Riviera Maya & Privado & 0.51 & Menos de 2,500 & Muy bajo-bajo \\
\hline Clínica COSTAMED & Privado & 1.89 & Menos de 2,500-9,999 & Muy Bajo-Medio \\
\hline Clínica Médica del Carmen & Privado & 3.66 & Menos de 2,500-4,999 & Muy Bajo-Medio \\
\hline Unidad de Medicina Familiar 11 & Público & 0.45 & $2,500-4,999$ & Bajo-Medio \\
\hline Unidad de Medicina Familiar & Público & 1.15 & Menos de 2,500-9,999 & Bajo \\
\hline Hospital AMERIMED & Privado & 0.61 & $2,500-14,999$ & Bajo-Alto \\
\hline Hospital PLAYAMED & Privado & 0.08 & $2,500-9,999$ & Bajo-Medio \\
\hline Clínica Santa Fe & Privado & 1.08 & Menos de 2,500-14,999 & Medio-Alto \\
\hline Centro de Salud Urbano No. 1 & Público & 1.88 & Menos de 2,500-14,999 & Medio-Alto \\
\hline Centro de Salud Urbano No. 2 & Público & 4.48 & $\begin{array}{c}\text { Menos de 2,500-Más de } \\
15,000\end{array}$ & Muy bajo-Alto \\
\hline Centro de Salud Urbano No. 3 & Público & 0.6 & Más de 15,000 & Alto \\
\hline Hospital General & Público & 4.34 & $\begin{array}{c}\text { Menos de 2,500-Más de } \\
15,000\end{array}$ & Muy bajo-Alto \\
\hline Unidad de Especialidad Médica & Público & 2.21 & $\begin{array}{c}\text { Menos de 2,500-Más de } \\
15,000\end{array}$ & Alto \\
\hline Hospital General de Zona No. 18 & Público & 3.96 & $\begin{array}{c}\text { Menos de 2,500-Más de } \\
15,000\end{array}$ & Muy bajo-Medio \\
\hline
\end{tabular}

Fuente: elaboración propia.

Como se observa en la figura 7 y en el cuadro 2, la ciudad de Playa del Carmen cuenta con menor cantidad de unidades de salud que Cancún. Sólo un AGEB, ubicado al norte de la ciudad, arroja grado de marginación Muy alto con una densidad poblacional de máximo 5,000 hab/km2, según la categoría obtenida en la figura 7, en donde se muestra que no hay presencia de centros de atención a la salud. La mayor cantidad de unidades de salud están ubicadas hacia la zona sur de Playa del Carmen.

Algunos de estos centros abarcan áreas de gran extensión con grado de marginación de Medio a Alto y densidad poblacional de más de 15,000 hab/km2, como son los casos del Hospital General (4.34 km2), el Hospital General de Zona No. 18 (3.96 km2), y los Centros de Salud Urbanos No. 1 y No. 2 (1.88 km2 y 4.48 km2, respectivamente) con densidad de población de más de 15,000 hab/km2 y grado de marginación que varía de Muy bajo a Muy alto sobre todo en los AGEB cercanos a la línea de costa (ver cuadro 2). 
Figura 8. Mapa del área de influencia de las unidades de salud, GMU (2010) y densidad de población para la ciudad de Tulum

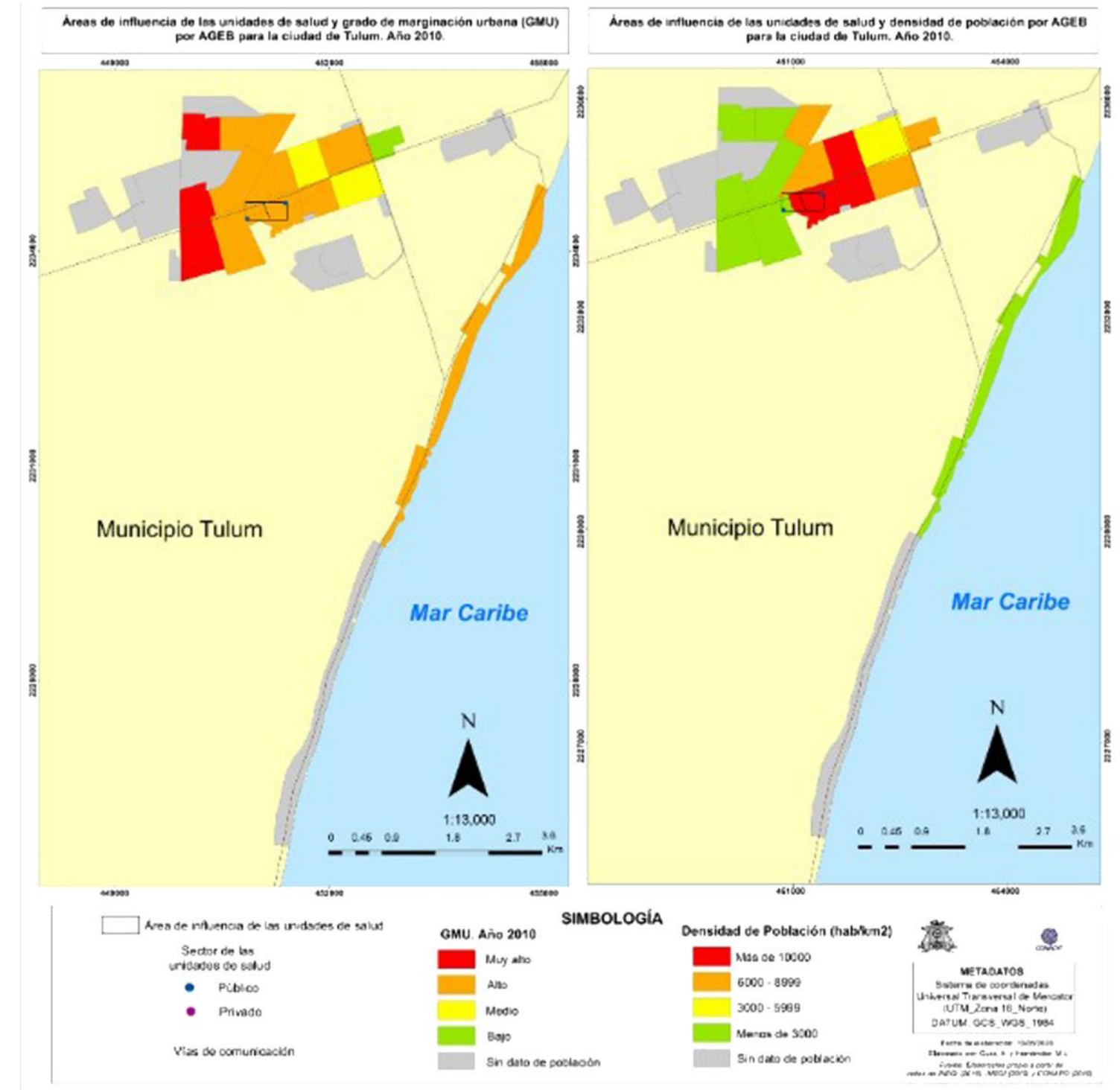

Fuente: elaboración propia con base en datos de INEGI (2010 y 2019) y CONAPO (2010).

Cuadro 3. Densidad y grado de marginación urbana por unidades de salud y su área de influencia para la ciudad de Tulum

\begin{tabular}{ccccc}
\hline POLígonos & SECTOR & $\begin{array}{c}\text { ÁREA DE INFLUENCIA } \\
\left(\mathbf{k m}^{2}\right)\end{array}$ & $\begin{array}{c}\text { DENSIDAD } \\
\left(\mathbf{h a b} / \mathbf{k m}^{2}\right)\end{array}$ & GMU \\
\hline $\begin{array}{c}\text { Unidad de Especialidad } \\
\text { Médica }\end{array}$ & Público & 0.07 & Menos de $3,000-$ & 8,999 \\
Centro de Salud Urbano & Público & 0.07 & Más de 10,000 & Alto \\
\hline
\end{tabular}

Fuente: elaboración propia. 
Según la figura 8 y el cuadro 3, la ciudad de Tulum cuenta solamente con dos unidades de salud para la atención a la población de todo el territorio. Ambas unidades del sector público están ubicadas en el centro de la ciudad con áreas de influencia de poca extensión, grado de marginación Alto y valores de densidad poblacional de 10,000 $\mathrm{hab} / \mathrm{km} 2$, según la categoría obtenida en la figura 8.

Figura 9. Mapa del área de influencia de las unidades de salud, GMU (2010) y densidad de población para la ciudad de

\section{Chetumal}

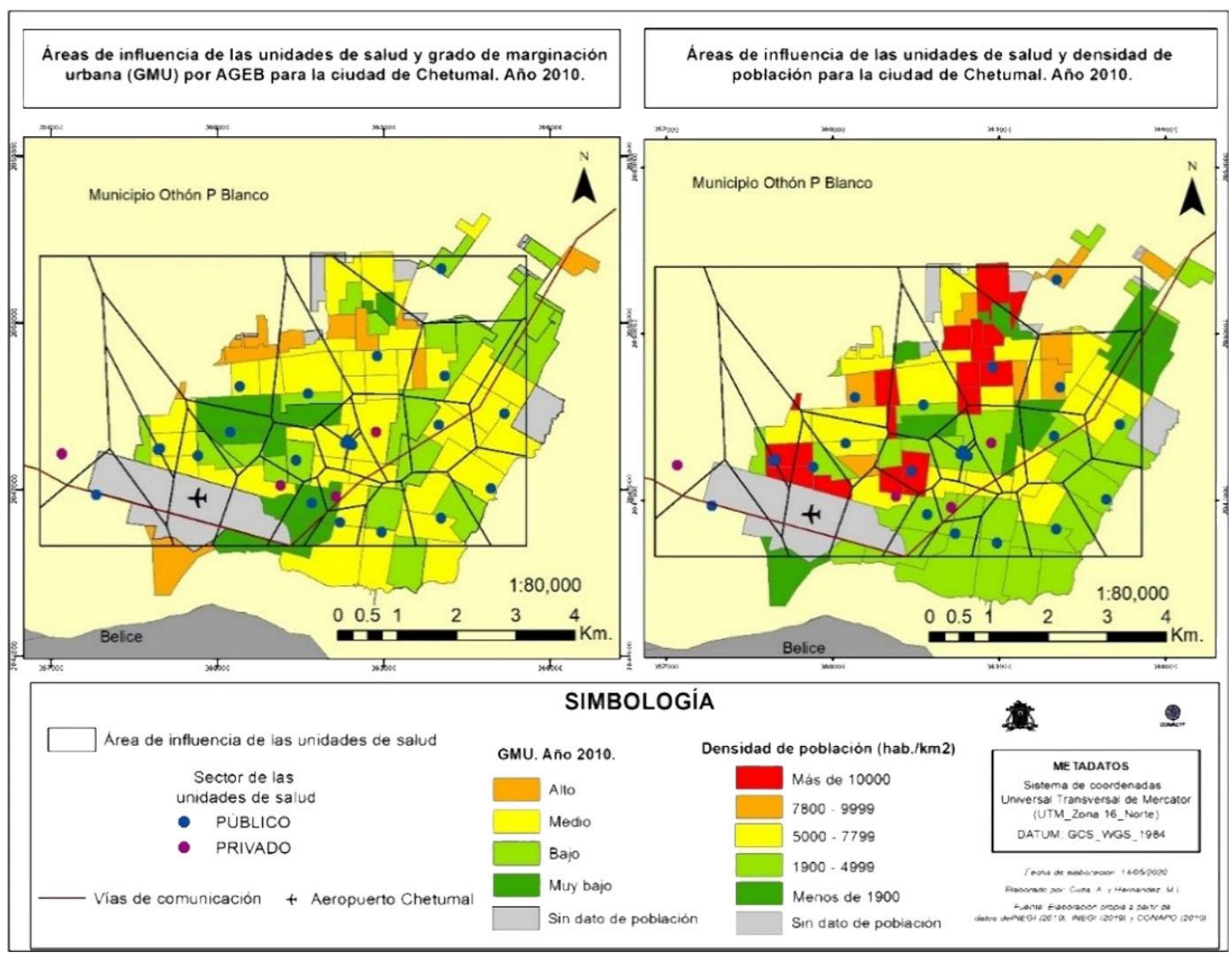

Fuente: elaboración propia con base en datos de INEGI (2010 y 2019) y CONAPO (2010). 
AÑO 23, 2021-1 ENERO-JUNIO E-ISSN 2594-102X PÁGS. 49-71

Cuadro 4. Densidad y grado de marginación urbana por unidades de salud y su área de influencia para la ciudad de Chetumal

\begin{tabular}{|c|c|c|c|c|}
\hline \multirow[b]{2}{*}{ POLÍGONOS } & \multicolumn{3}{|c|}{ ÁREA DE } & \multirow[b]{2}{*}{ GMU } \\
\hline & SECTOR & $\begin{array}{l}\text { INFLUENCIA } \\
\left(\mathbf{k m}^{2}\right)\end{array}$ & $\begin{array}{c}\text { DENSIDAD } \\
\left(\mathbf{h a b} / \mathbf{k m}^{2}\right)\end{array}$ & \\
\hline Centro de Rehabilitación Integral & Privado & 4.69 & Sin datos & Sin datos \\
\hline Clínica Campestre & Privado & 1.57 & 1900-Más de 10,000 & Muy bajo-Medio \\
\hline Clínica Santa Teresa & Privado & 1.18 & Menos de 1,900-4,999 & Bajo-Medio \\
\hline Clínica Carranza & Privado & 0.6 & $1,900-7,799$ & Muy bajo-Medio \\
\hline Centro de Atención Médica & Público & 2.12 & $5,000-9,999$ & Bajo-Alto \\
\hline Unidad de Especialidad Médica DEDICAM & Público & 2.61 & Sin datos & Sin datos \\
\hline Centro de Salud Urbano No. 6 & Público & 1.59 & 1,900-Más de 10,000 & Bajo-Medio \\
\hline Unidad de Especialidad Médica SORID & Público & 1.84 & 5,000-Más de 10,000 & Bajo-Medio \\
\hline Centro de salud Urbano No. 4 & Público & 1.96 & 1,900-Más de 10,000 & Bajo-Medio \\
\hline Clínica Hospital ISSSTE & Público & 1.08 & $1,900-7,799$ & Muy bajo-Medio \\
\hline Centro de Salud Urbano No. 3 & Público & 0.83 & 1,900-Más de 10,000 & Muy bajo-Medio \\
\hline Hospital General de Zona 1 & Público & 0.7 & $1,900-4,999$ & Muy bajo \\
\hline Unidad Médica Móvil & Público & 0.54 & $1,900-4,999$ & Muy bajo-Medio \\
\hline Hospital Materno Infantil Morelos & Público & 0.87 & $1,900-4,999$ & Bajo-Medio \\
\hline Centro Regional de Desarrollo Infantil & Público & 1.45 & $1,900-7,799$ & Bajo-Medio \\
\hline Unidad de Especialidad Médica CISAME & Público & 0.37 & $1,900-7,799$ & Medio \\
\hline Unidad de Especialidad Médica CAPA & Público & 0.32 & $1,900-7,799$ & Medio \\
\hline Unidad de Especialidad Médica CAPASIT & Público & 0.02 & $1,900-4,999$ & Muy bajo-Medio \\
\hline Hospital General & Público & 0.29 & Menos de 1,900-7,799 & Medio \\
\hline Hospital Militar de Zona & Público & 1.82 & $1,900-4,999$ & Bajo-Medio \\
\hline Hospital Naval & Público & 1.41 & Menos de 1,900-7,799 & Bajo-Medio \\
\hline Centro de Salud Urbano No. 2 & Público & 1.69 & Menos de 1,900-7,799 & Bajo-Medio \\
\hline Centro de Salud Urbano No. 1 & Público & 3.61 & Menos de 1,900-Más de 10,000 & Muy bajo-Alto \\
\hline Clínica de Especialidades & Público & 2.23 & Menos de 1,900-Más de 10,000 & Muy bajo-Alto \\
\hline Centro de Salud Urbano No. 7 & Público & 7.17 & 1,900-Más de 10,000 & Muy bajo-Alto \\
\hline Centro de salud Urbano Las Américas & Público & 3.2 & Menos de 1,900-Más de 10,000 & Bajo-Medio \\
\hline
\end{tabular}

Fuente: elaboración propia.

En la ciudad de Chetumal, la situación parece ser diferente a la de las ciudades anteriores con respecto a la distribución espacial de las unidades de salud. En Chetumal, los centros de atención a la salud están abarcando la mayor parte de los AGEB (ver figura 9). El caso del Centro de Salud Urbano No. 7 que tiene un área de influencia de 7.17 km2, abarcando AGEB de más de 10,000 hab/km2 y grado de marginación Alto. 


\section{Discusión}

Como parte de la bibliografía consultada para la confección de este trabajo, no se encontraron muchos trabajos que apliquen la metodología Thiessen dentro del campo de la Geografía de la Salud. Sin embargo, diversos autores, como Aragón et al. (2018); Pizarro, Ramírez y Flores (2003), emplean esta metodología en el campo de la hidrología, sobre todo para el estudio, análisis y estimaciones de variables hodrológicas. Por otra parte, Buzai (2016), con su estudio de áreas de influencia de los centros médicos en la ciudad de Luján, nos dio la pauta que necesitábamos para unir esta metodología de polígonos Thiessen con variables sociales bajo el enfoque de la Geografía de la Salud. Derivado de este análisis, el presente trabajo puede ser una aportación a los estudios de aplicación de polígonos Thiessen en el campo de la Geografía de la Salud.

Si bien este estudio nos da una aproximación interesante sobre la situación actual de cada ciudad, partiendo del análisis de los mapas y cuadros anteriores, podemos afirmar que en las cuatro ciudades estudiadas, hay AGEB que no cuentan con la presencia de centros de atención a la salud, por lo que las personas que habitan en estas áreas se ven obligadas a trasladarse hacia las zonas de la ciudad donde se ubican los hospitales, clínicas y centros de atención, aumentando el riesgo de contagio por el traslado de grandes distancias. Por su parte, la ciudad de Tulum presenta mayor carencia, pues sólo cuenta con dos unidades de salud en su territorio.

En la ciudad de Cancún existen gran cantidad de unidades de salud, divididas entre sector privado y sector público, dedicadas a atender diferentes especialidades, según la información empleada de INEGI (2019). La ciudad cuenta con 46 unidades de salud, siendo la mayoría del sector público, las cuales están distribuidas en el centro del territorio; más concentradas hacia las zonas noreste. Las unidades del sector privado que se identificaron se localizan al sureste; más cercanas a la zona hotelera.

Según las categorías obtenidas en la figura 6, la distribución de las unidades abarca áreas de la ciudad que cuentan con grado de marginación urbana Bajo hacia la zona sur, partiendo de la vía de comunicación principal que atraviesa la ciudad; mientras que hacia el norte el grado de marginación aumenta desde Medio hasta Muy alto y se encuentra la menor cantidad de unidades de salud.

Sin embargo, en la zona que arroja el grado de marginación Muy alto no hay existencia de unidades de salud, de acuerdo con la información con que se pudo trabajar. Por otra parte, en cuanto a los valores de densidad poblacional, Cancún cuenta con áreas donde la densidad poblacional es de más de 15,000 hab/ km2 por AGEB, en contraposición de áreas que presentan menos de 2,500 hab/ km2, como el suroeste de la ciudad, debido al crecimiento de la ciudad con recientes asentamientos. Las áreas de influencia de las unidades de salud abarcan, en su mayoría, el centro de la ciudad, observándose en algunas unidades mayor cantidad de población a la cual dar atención médica. 
Por su parte, en la ciudad de Playa del Carmen, la cantidad de unidades de salud se reduce bastante en comparación con Cancún. La distribución de las 14 unidades está más concentrada hacia el sur de la ciudad en áreas donde el grado de marginación va de Muy bajo a Alto, según las categorías obtenidas (ver figura 7 y cuadro 2), mientras que en las zonas de Muy alto grado de marginación no existen unidades de salud. En los AGEB cercanos a la zona costera que cuentan con valores de densidad poblacional de más de 15,000 hab/ $\mathrm{km} 2$, sólo hay presencia de un centro de salud urbano y una unidad de especialidades médicas. En la zona norte de la ciudad, sólo hay una unidad médica.

La ciudad de Tulum es la que se encuentra en mayor desventaja, pues sólo cuenta con dos unidades de salud para dar atención médica a una gran cantidad de personas que residen en esta ciudad o están de forma temporal. Ambas unidades están ubicadas en zonas con grado de marginación Alto y una densidad de población de más de 10,000hab/km2.

En la ciudad de Chetumal prevalece el grado de marginación Medio; no existen zonas de Muy alto grado de marginación, aunque sí de densidad poblacional de más de 10,000 hab/ km2. La distribución de las unidades de salud es bastante equitativa a lo largo de la ciudad; sin embargo, algunas unidades se verían recargadas por la gran densidad de población que deben atender; por ejemplo, el centro de salud No. 1, el cual está ubicado en una zona de AGEB donde la densidad poblacional es de más de 10,000 hab/km2, mientras que hay hospitales y clínicas ubicadas cercanas unas de otras en zonas donde la población es menor.

\section{Conclusiones}

Al comparar las cuatro ciudades costeras, elegidas para este análisis, se puede concluir que Cancún cuenta con una mayor cantidad de unidades de salud, pero, a la vez, es la de mayores valores de densidad de población. Tulum, por su parte, al ser una ciudad costera de la región del Caribe Mexicano, cuenta con una de las tasas más altas de crecimiento demográfico del país a causa del impulso de las actividades turísticas. Además, es la ciudad con mayor desventaja en el acceso a servicios de salud, ya que solamente cuenta con dos clínicas de salud para una población con una densidad mayor de 10,000 hab/km2.

Esta falta de instalaciones médicas en Tulum es y será un problema para la atención a la población, pues, por su gran actividad turística, su crecimiento poblacional continuará en aumento representando más demandas sociales. Los problemas de marginación derivados de este rápido crecimiento demográfico y urbano son la poca oportunidad de empleo, la incidencia de huracanes, bajos salarios, escasez de vivienda y poca oportunidad de obtenerla, así como los servicios de mala calidad (Chávez, 2018), a todo esto se le suma la falta de unidades de atención a la salud, por lo que la población se encuentra mucho más vulnerable ante el enfrentamiento de amenazas de origen natural o antrópico. 
Con respecto a las variables vinculadas al estudio, se pueden encontrar clínicas privadas establecidas en áreas con Alta marginación y centros de salud pública ubicados en zonas con alta y muy alta densidad poblacional que, bajo los efectos de una situación de pandemia como la que se está viviendo, su capacidad de atención llegaría a saturarse, siendo necesario crear nuevas unidades de servicios de la salud o la reconversión de espacios públicos a unidades de salud.

La capacidad de recepción de un hospital no sólo se vincula al número de camas disponibles, sino también a prestar atención médica. Por lo tanto, se debe respaldar con un mejor conocimiento de la movilidad de pacientes, las emergencias, el trabajo y los productos de un hospital, los obstáculos que se producen y la traducción de esta interpretación en nuevas herramientas de planificación.

El análisis de áreas de influencia presentado permitió observar el alcance y la distribución espacial de servicios hospitalarios públicos o privados en ciudades costeras. Como se demostró, la metodología empleada permitió observar las áreas de cobertura de las unidades de salud, tanto públicas como privadas, y la correlación de datos con las variables utilizadas, poniendo en evidencia la compleja situación que existe en las ciudades de estudio con respecto a la desproporción entre oferta y demanda de servicios de salud, convirtiéndose en un importante motivo de preocupación para los ciudadanos, pero también para los profesionales y los responsables de las políticas sanitarias.

\section{Agradecimientos}

Los agradecimientos van dirigidos a la Universidad de Quintana Roo y a la Comisión Nacional de Ciencia y Tecnología (CONACYT) por el apoyo económico con la beca como estudiante del Doctorado en Geografía.

\section{Referencias}

Aragón, J.L, Aguilar, G., Velázquez, U., Jiménez, M. y Maya, F. (2018). Distribución espacial de variables hidrológicas. Implementación y evaluación de métodos de interpolación. Revista Ingeniería, Investigación y Tecnología. XX(2), abril-junio, pp. 1-15. México: UNAM

Buzai, G. y Baxendale, C. (2006). Análisis socio espacial con sistemas de información geográfica. Grupo de Ecología del Paisaje y Medio Ambiente. Universidad de Buenos Aires, Argentina.

Buzai, G. (2016). Áreas de influencia de los centros de atención primaria de salud (CAPS) en la ciudad de Luján mediante polígonos de Voronoi-Thiessen. Revista Investigaciones y ensayos geográficos. XIII(13), 11-25.

Castro, L. (2018). Exclusión social, marginación y pobreza. Tópicos vigentes. México: Fontamara.

Chávez Alvarado, R. (2018). Gestión del riesgo de desastre en el caribe mexicano. El caso de estudio de Chetumal, Quintana Roo. Revista de Estudios Latinoamericanos sobre Reducción del Riesgo de Desastres REDER, 2(2), 46-60. Recuperado de: http:/ / www.revistareder.com/ojs/index.php/reder/article/view/17

CONAPO (2000). Índice de marginación 2000. México: Consejo Nacional de Población.

CONAPO (2010). Índice de marginación urbana 2010. México: Consejo Nacional de Población. 


\section{AÑO 23, 2021-1 ENERO-JUNIO E-ISSN 2594-102X PÁGS. 49-71 LPË.}

CONAPO. (2013). Índice absoluto de marginación 2000-2010. México: Consejo Nacional de Población. Recuperado de: http://www.conapo.gob.mx/work/models/CONAPO/Resource/1755/1/images/00Presentacion.p $\mathrm{df}$

CONAPO. (2019). Estimaciones y proyecciones de la población por sexo y edad a mitad de año. Quintana Roo Período 2010-2030. México: Consejo Nacional de Población. Recuperado de: http://coespo.qroo.gob.mx/Descargas/doc/PUBLICACCIONES\%20DE\%20INTERES/POBLACION _QROO_2019.pdf

Cuthill, F. (2019). Homelessness, Social exclusion and health: Global perspectives, local solutions. Dunedin: Dunedin Academic Press.

Debnath, M. (2020). A community under siege: exclusionary education policies and indigenous Santals* in the Bangladeshi context. Third World Quarterly, 41(3), 453-469. doi:doi.org/10.1080/01436597.2019.1660634

Durkheim, E. (1982). El suicidio. Madrid: Akal.

Elias, N. y Scotson, J. (2015). Establecidos y marginados. Una investigación sociológica sobre problemas comunitarios. México: Editorial del Fondo de Cultura Económica.

Herrero, S. (2018). Condiciones de salud en las comunidades marginadas y aisladas contactadas de América Latina. Academo, 5(1), 13-34. Recuperado de: https://uamericana.edu.py/revistacientifica/index.php/academo/article/view/84/81

Howe, M. (1986). La Geografía Médica. Fondo de cultura económica. México.

Instituto Mexicano del Transporte. (2010). Análisis comparativo de tres métodos para la delimitación del área de influencia de un aeropuerto. Notas. 123, marzo- abril. Recuperado de: https://imt.mx/archivos/Boletines/Nota123.pdf

INEGI (2010). Censo de Población y Vivienda 2010. Principales resultados por localidad (ITER). México. Instituto Nacional de Estadística y Geografía. Recuperado de: www.inegi.gob.mx

INEGI. (2015). Encuesta intercensal. México. Instituto Nacional de Estadística y Geografía. Recuperado de: https://www.inegi.org.mx/programas/intercensal/2015/

INEGI. (2019). Directorio Estadístico Nacional de Unidades Económicas 2019. Datos a noviembre de 2019. México. Instituto Nacional de Estadística y Geografía. Recuperado de: https://www.inegi.org.mx/app/mapa/denue/

Loktieva, I. (2016). Approaches to empirical analysis of social exclusion: international comparison. Journal of Scientific Papers Economics \& Sociology, 9(2), 148-157. doi:10.14254/2071-789X.2016/9-2/10.

Nieto, C., Nicasio, R., Martín, R. y García, A. (2017). De la pobreza a la marginación. Relatos y discursos de personas en situación de marginalidad. Madrid: Dykinson.

Pizarro, R., Ramírez, C. y Flores, J. (2003). Análisis comparativo de cinco métodos para la estimación de precipitaciones areales anuales en períodos extremos. Bosque (Valdivia), 24(3), 31-38. https://dx.doi.org/10.4067/S0717-92002003000300003

Quijano, A. (1972). La constitución del "mundo" de la marginalidad urbana. EURE, 5(2), 89-106. Recuperado de http://www.eure.cl/index.php/eure/article/viewFile/837/685

Ramírez, M. (2017). La moderna geografía de la salud y las tecnologías de la información geográfica. Revista investigaciones y ensayos geográficos. IV(4), 53-64.

Reid, C. (2017). The wound of exclusion: Poverty, women's health, and social justice. New York: Routledge.

Reyna, A. (2006). El uso de los sistemas de información geográfica (SIG) en el análisis demográfico de situaciones de desastre. Notas de Población. XXXII(81). Recuperado de: https://repositorio.cepal.org/bitstream/handle/11362/12792/np81129162_es.pdf?sequence=1\&isAll owed $=\mathrm{y}$

Sánchez, N. (2017). Cálculo de la precipitación media sobre la península de la Guajira usando el método Thiessen. Revista Ciencia e Ingeniería Neogranadina. 26 (1). Bogotá, Colombia. 